Supplement of Hydrol. Earth Syst. Sci., 24, 3725-3735, 2020

https://doi.org/10.5194/hess-24-3725-2020-supplement

(C) Author(s) 2020. This work is distributed under

the Creative Commons Attribution 4.0 License.

(c) (1)

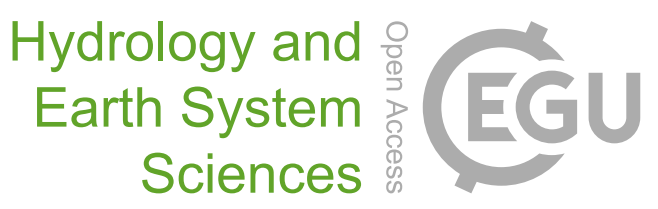

Supplement of

\title{
Climate-dependent propagation of precipitation uncertainty into the water cycle
}

\author{
Ali Fallah et al. \\ Correspondence to: Ali Fallah (alifallah@shirazu.ac.ir, afallah@bgc-jena.mpg.de)
}

The copyright of individual parts of the supplement might differ from the CC BY 4.0 License. 
Table S1: Summary of model parameters.

\begin{tabular}{ccc}
\hline Parameter & Meaning & Considered range \\
\hline Water holding capacity & Maximum water storage & $56-1485 \mathrm{~mm}$ \\
Runoff function exponent & $\begin{array}{c}\text { Sensitivity of (normalized) runoff } \\
\text { to soil moisture } \\
\text { ET function exponent }\end{array}$ & $0.53-15$ \\
maximum ET ratio & $\begin{array}{c}\text { Sensitivity of evaporative fraction } \\
\text { to soil moisture }\end{array}$ & $0.04-1.25$ \\
Melting parameter & $\begin{array}{c}\text { Maximum fraction of net radiation } \\
\text { that can be transformed into ET } \\
\text { Runoff delay }\end{array}$ & Speed of snow melting \\
& Conversion of runoff to streamflow & $0.30-0.99$ \\
\end{tabular}




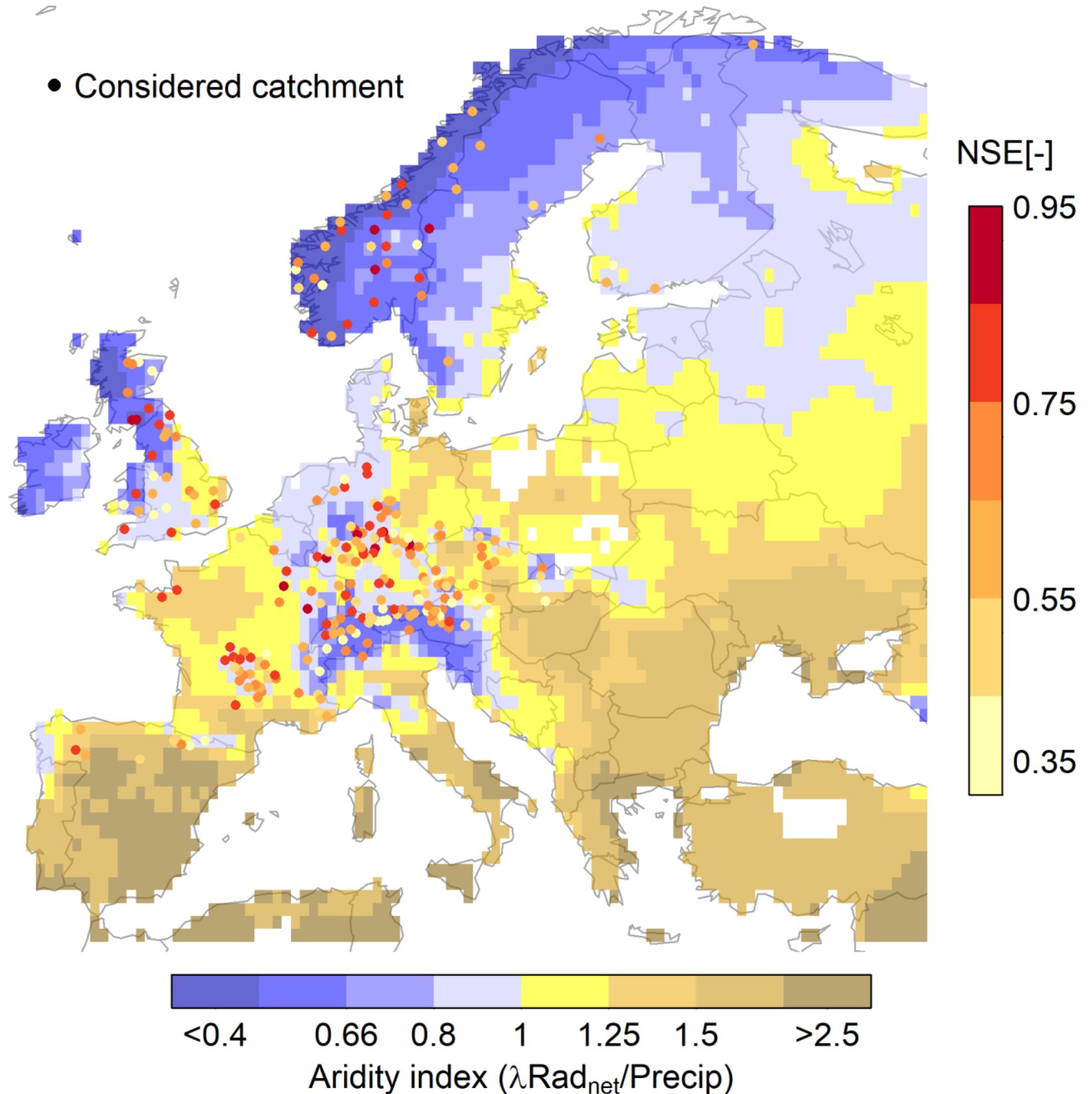

Figure S1: Same as figure 1 in the main text, but with NSE values obtained from the model calibration using E-OBS data. Only catchments where NSE $>=0.36$ are shown. 


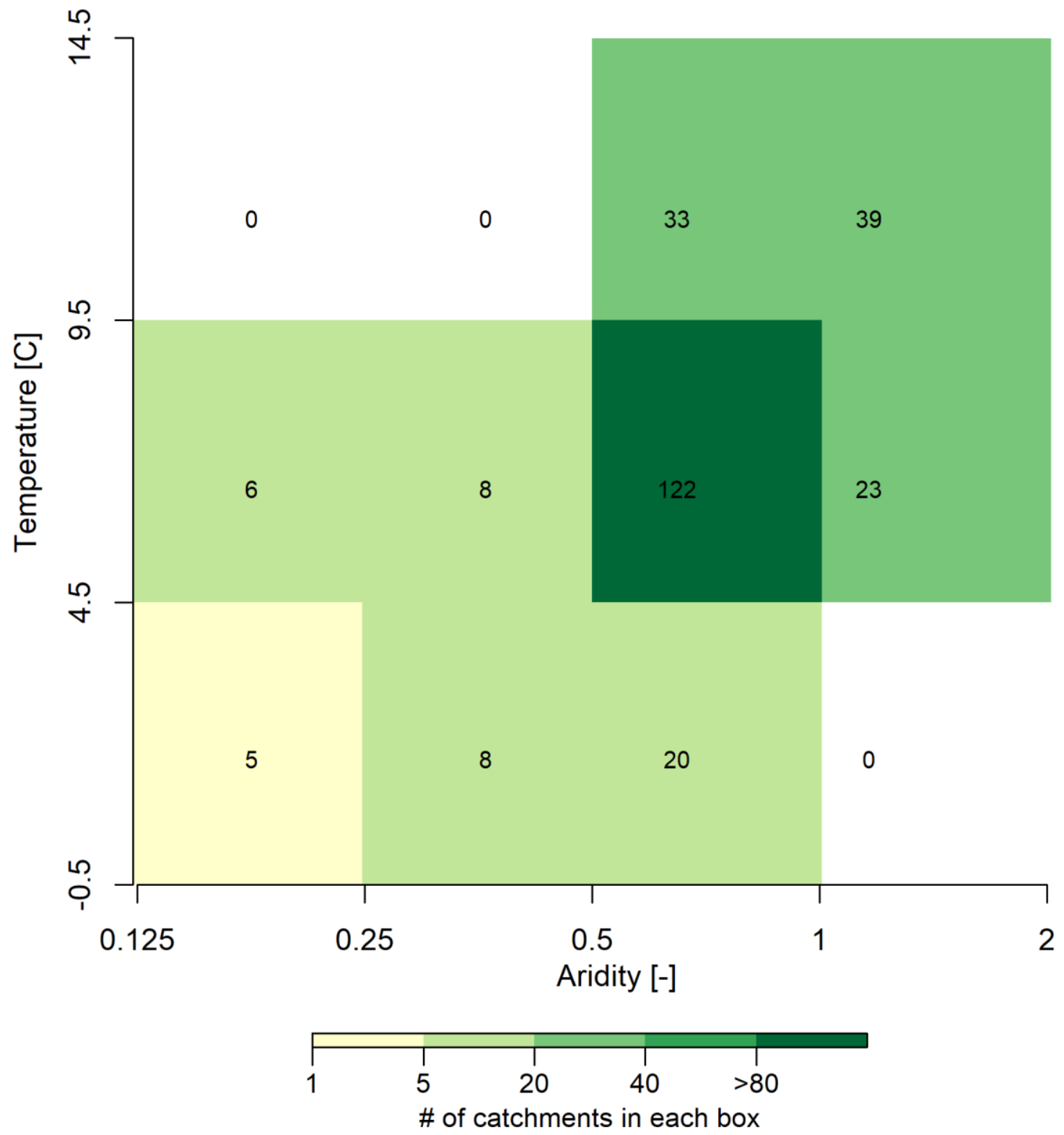

Figure S2: Number of considered catchments in each hydro-climatological regime at the monthly scale. Overall, 264 catchments across Europe are evaluated in this study. 


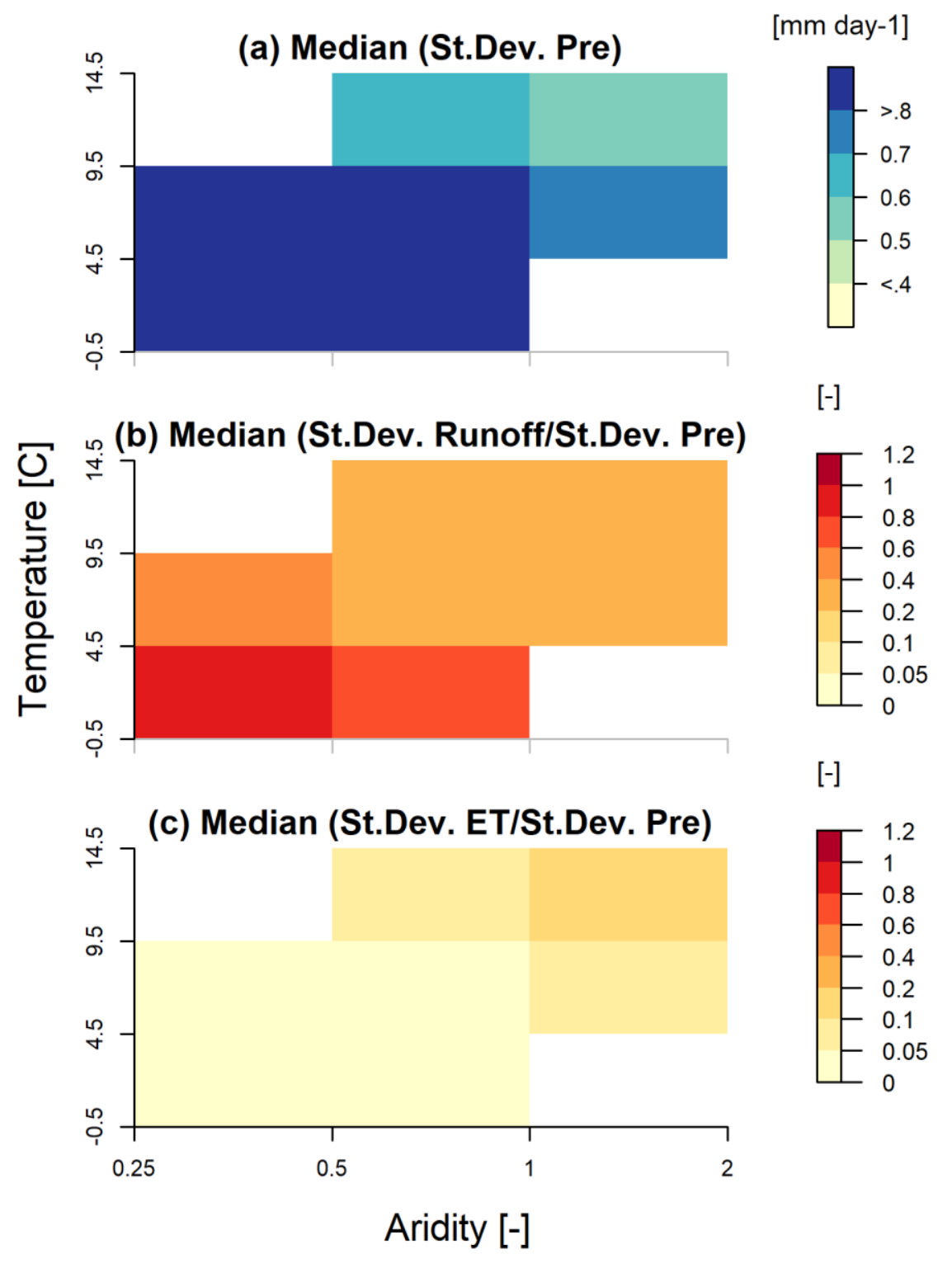

Figure S3: Same as figure 4 in the main text, but with results computed based on daily time series. 


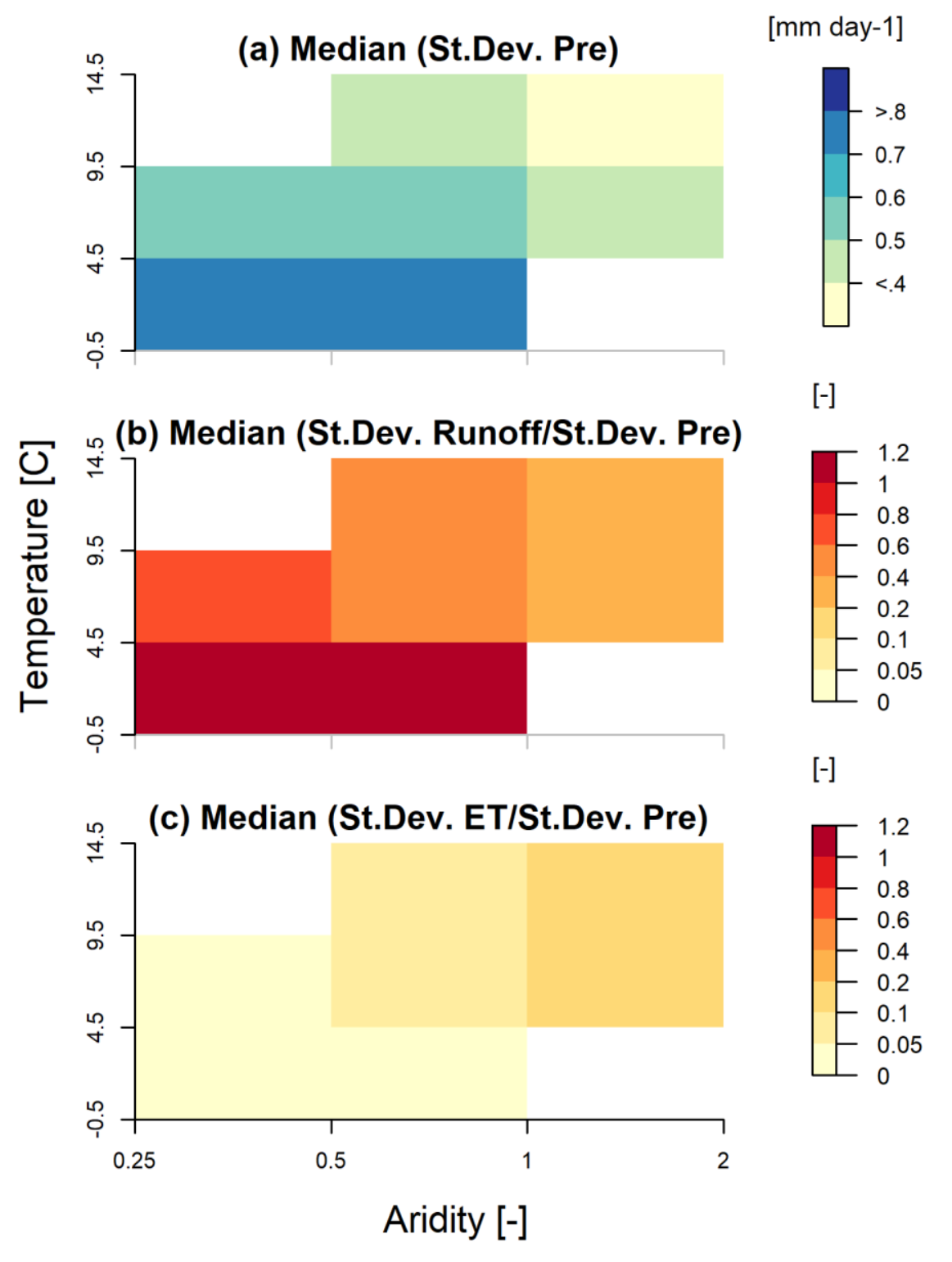

Figure S4: Same as figure 4 in the main text, but with results obtained from the model calibrated using GPCC precipitation data. 


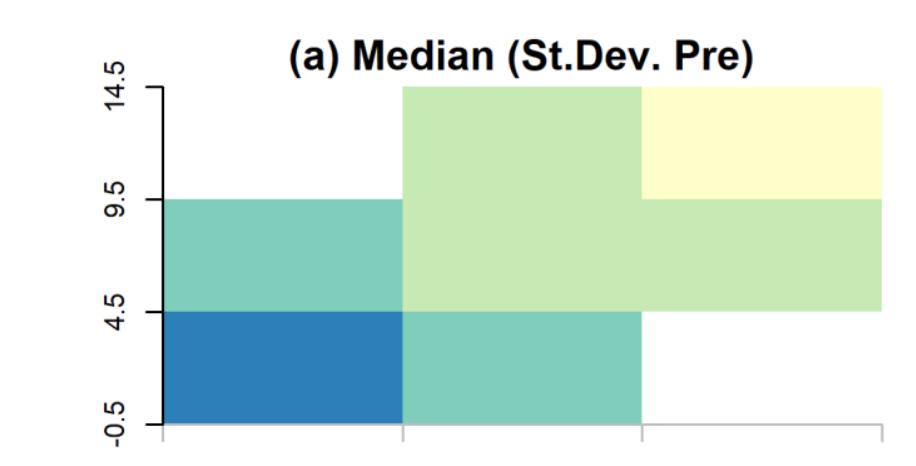

[mm day-1]
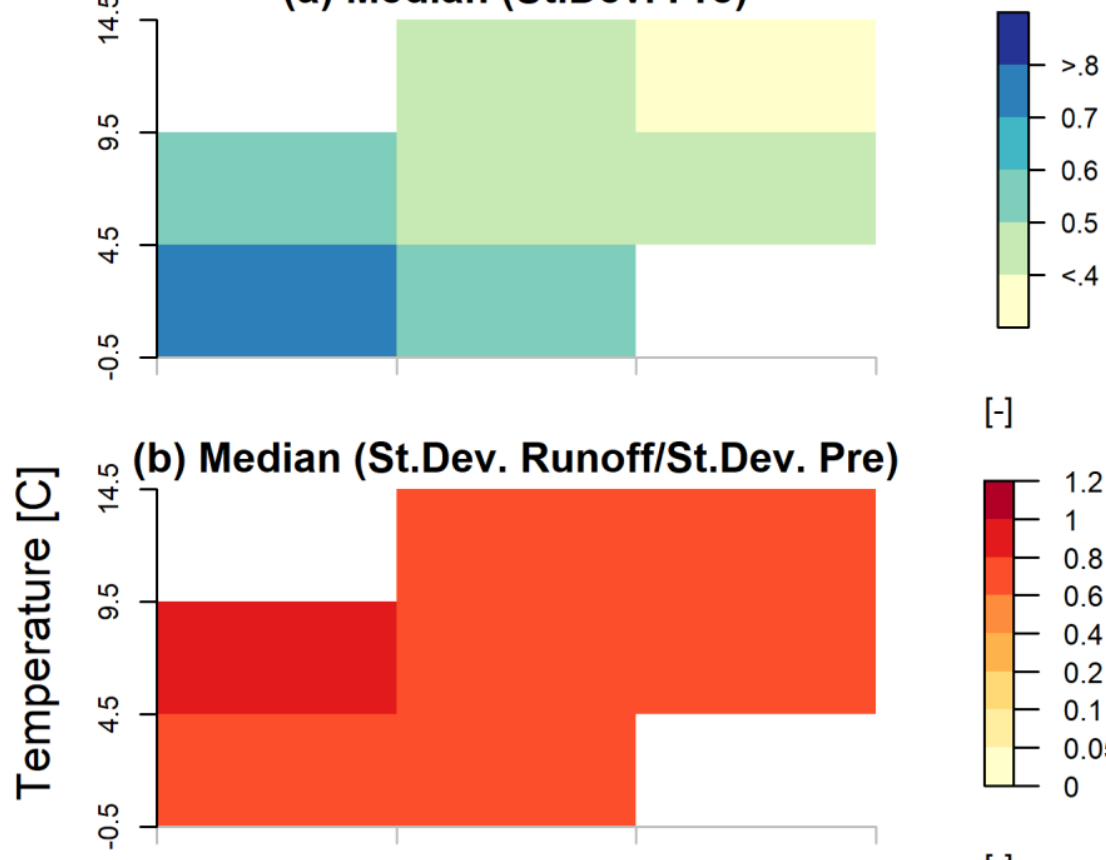

$[-]$

(c) Median (St.Dev. ET/St.Dev. Pre)

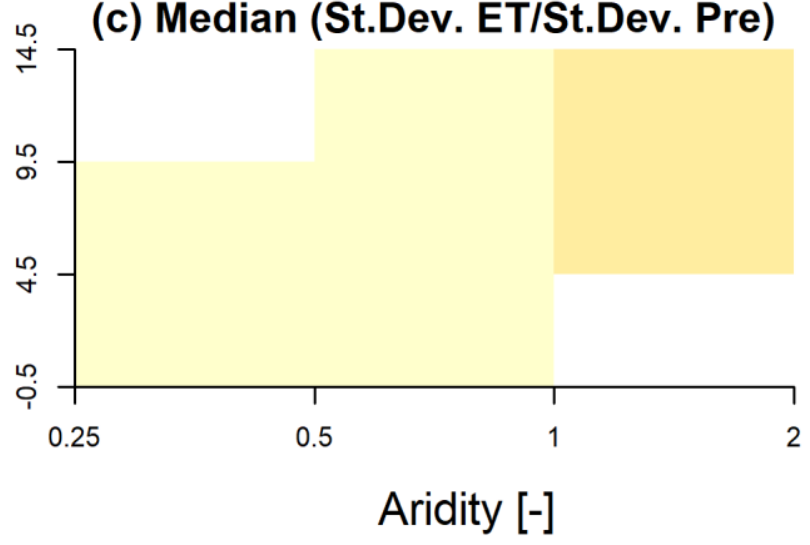

$[-]$

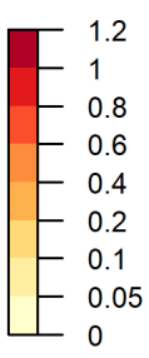

Figure S5: Same as figure 4 in the main text, but with results computed for whole year. 


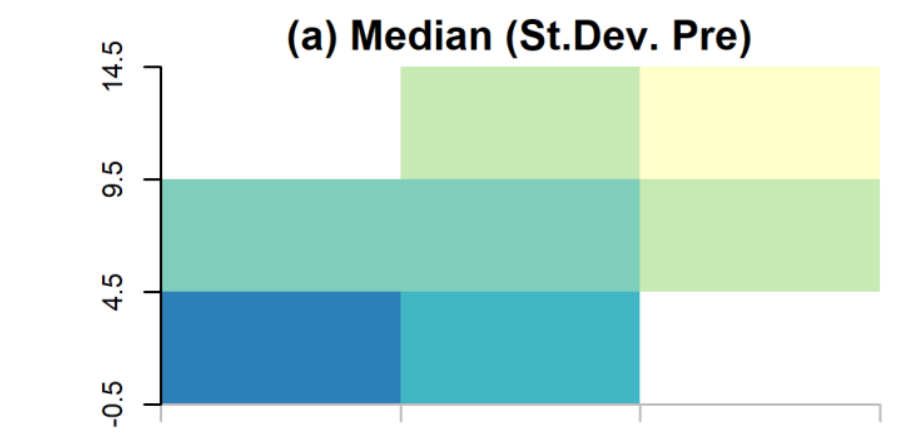

[mm day-1]
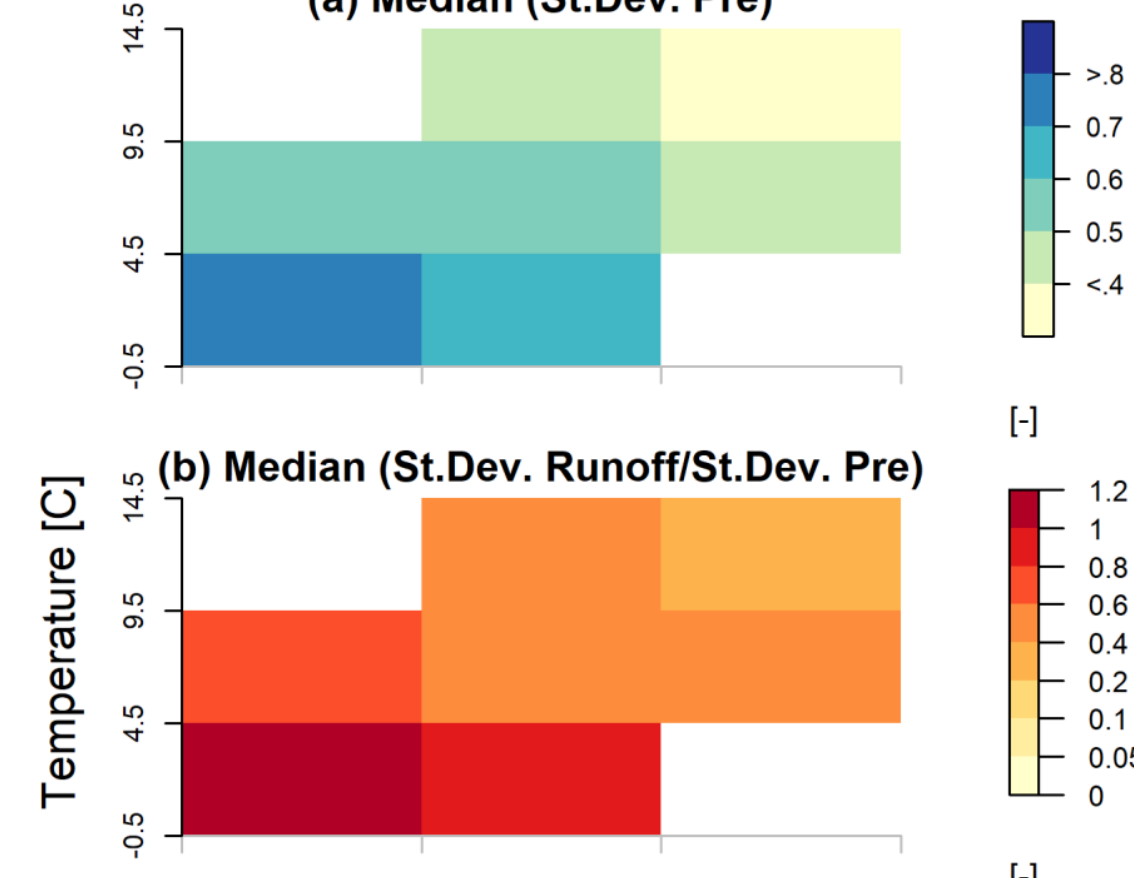

[-]
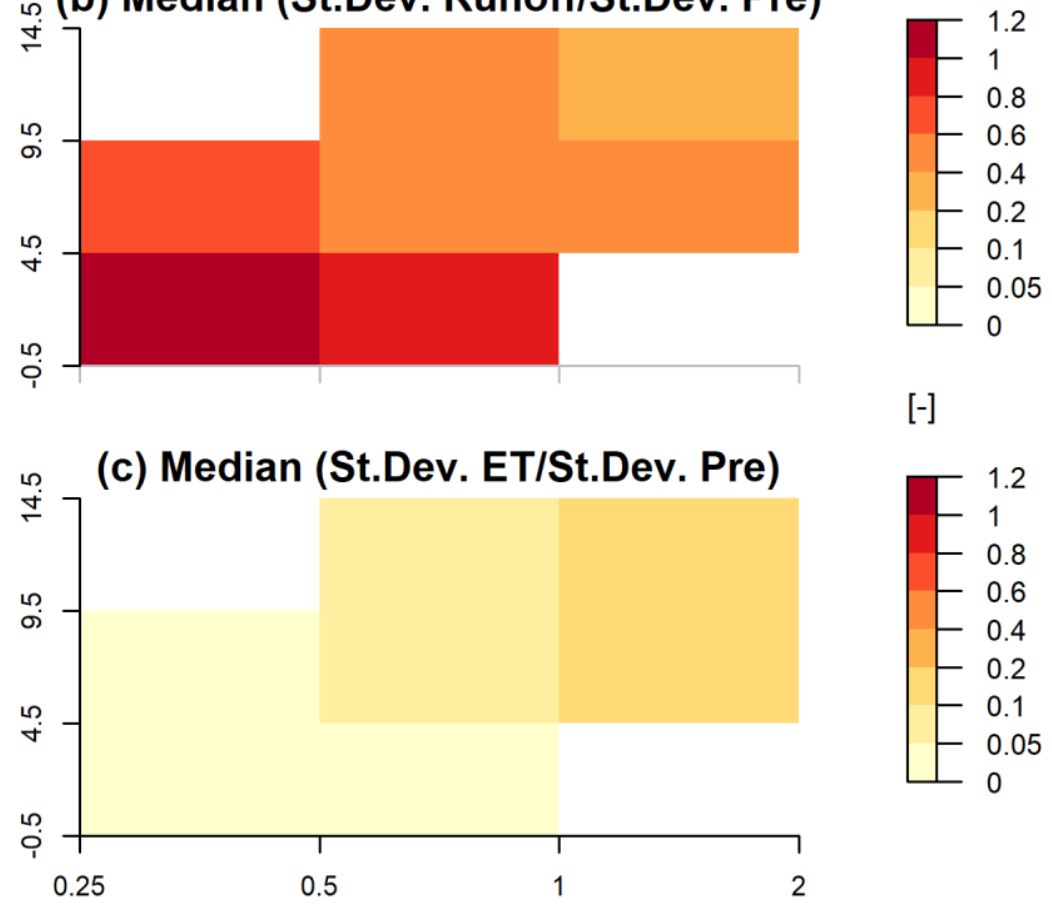

Aridity [-]

Figure S6: Same as figure 4 in the main text, but with results obtained from filtering catchments with NSE $>=0.5$. 


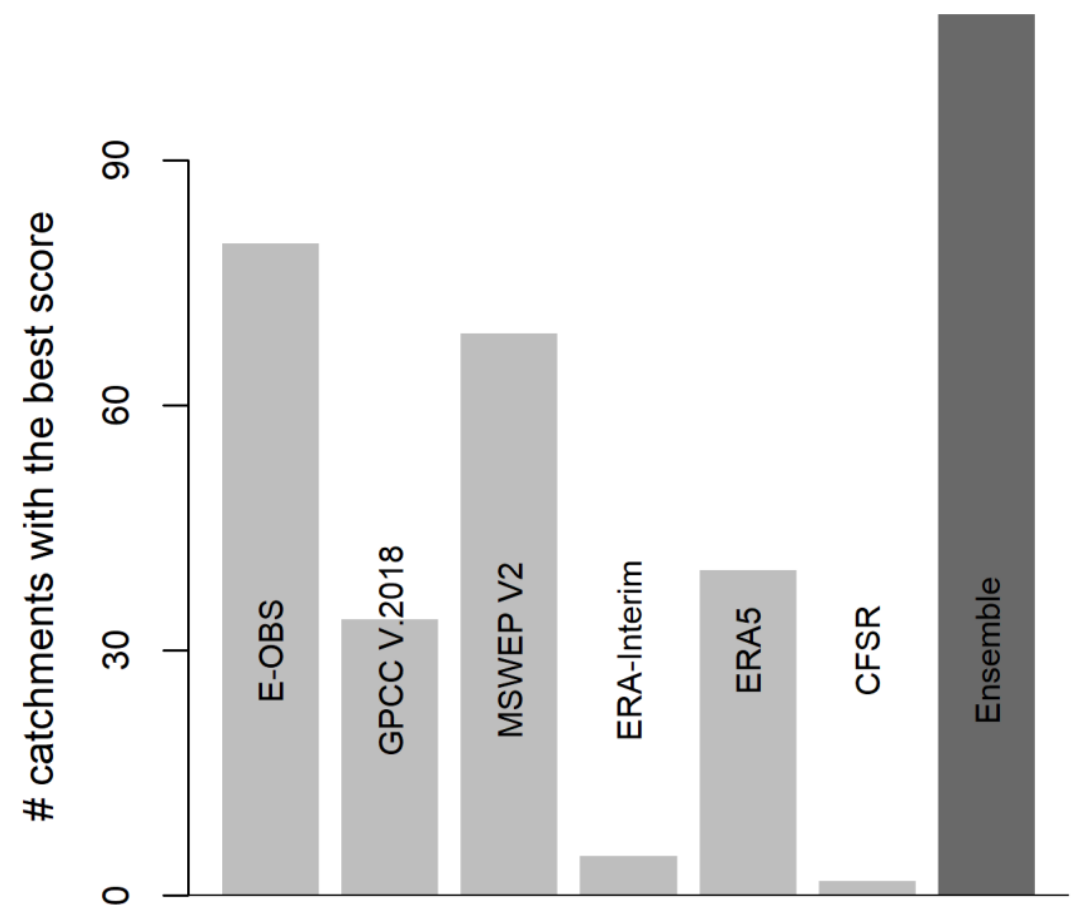

Figure S7: Same as figure 5 in the main text, but with results obtained from daily time series. 


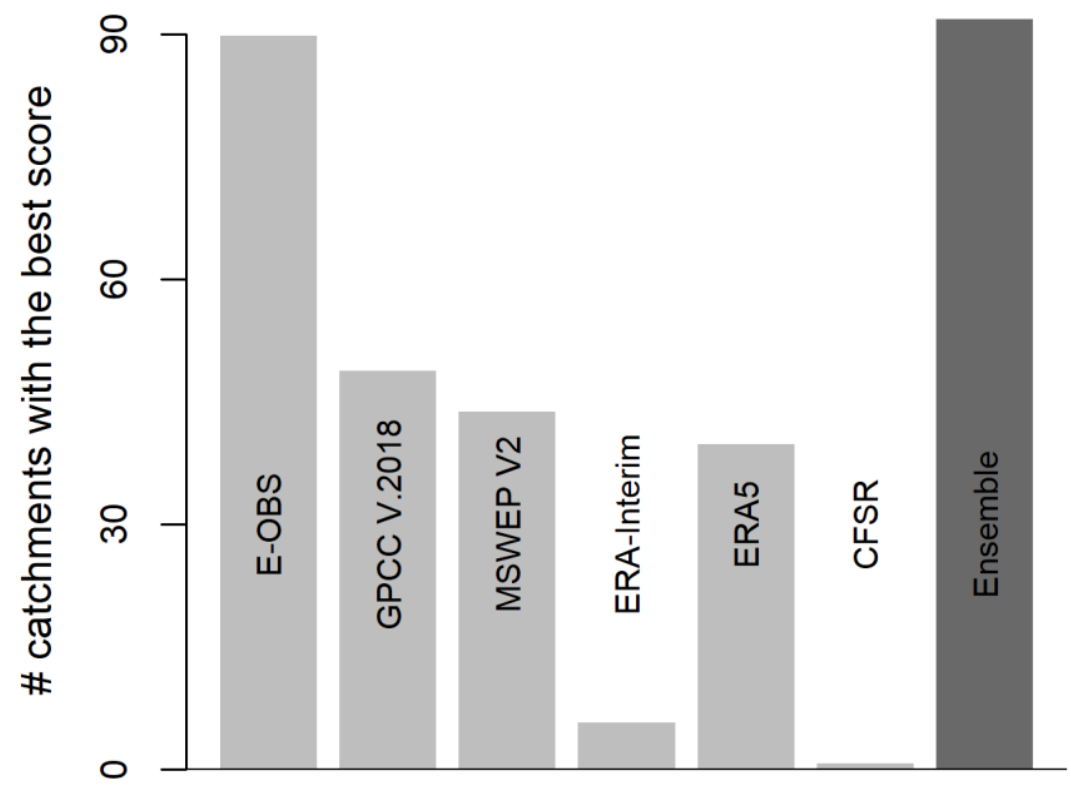

Figure S8: Same as figure 5 in the main text, but with results computed for whole year. 


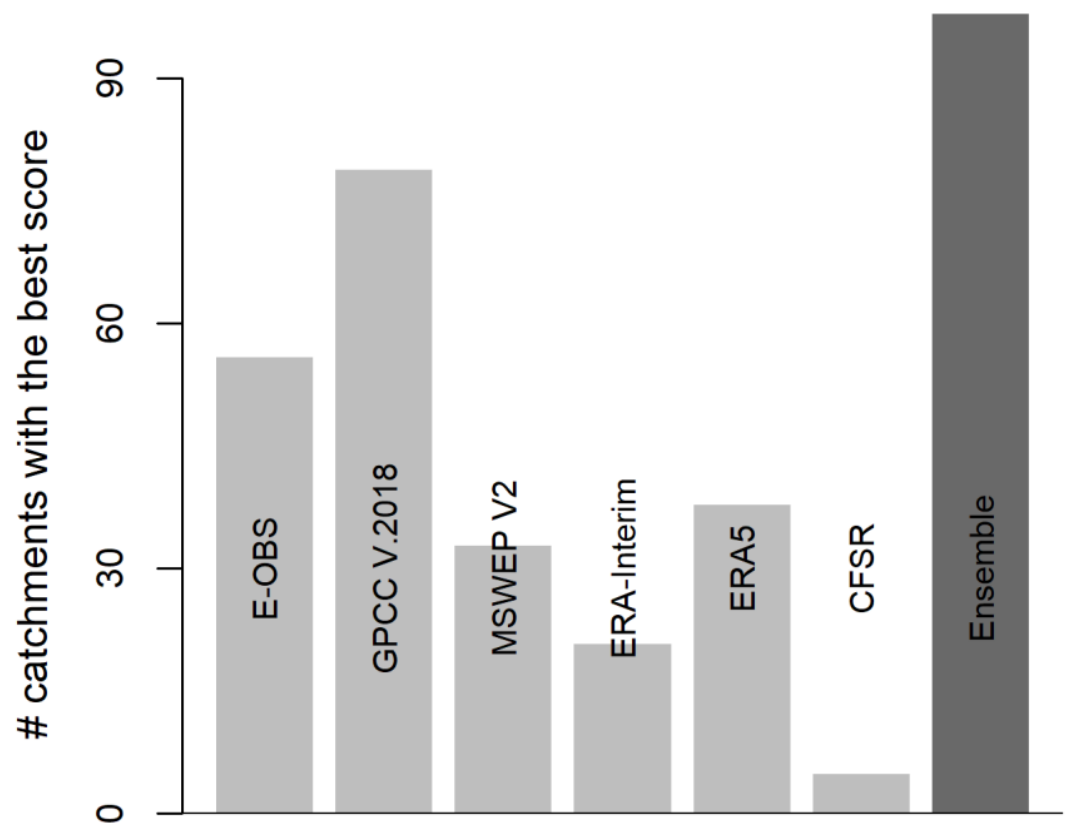

Figure S9: Same as figure 5 in the main text, but with results obtained from the model calibrated using GPCC precipitation data. 


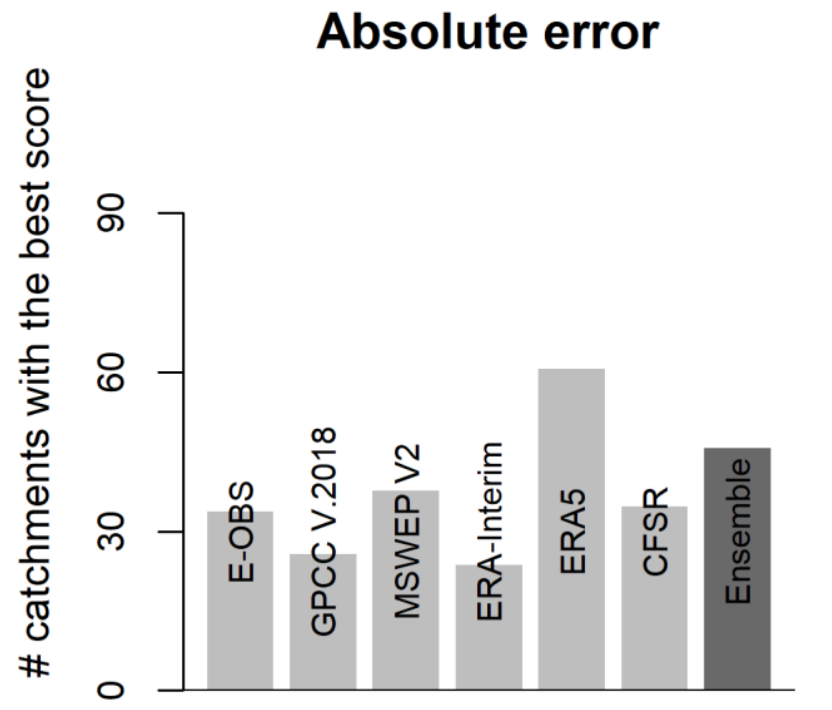

\section{Correlation}

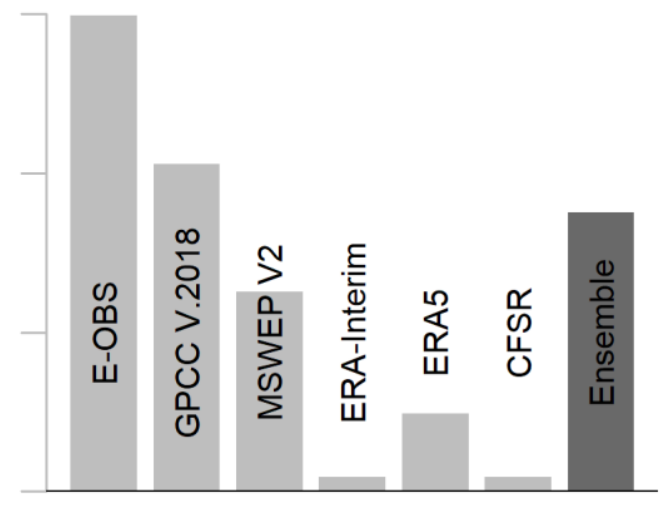

Figure S10: Same as figure S8, but with results obtained from absolute error and correlation separately. 